\title{
Rheological and filtration characteristics of drilling fluids enhanced by nanoparticles with selected additives: an experimental study
}

\author{
Nima Mohamadian ${ }^{1}$, Hamzeh Ghorbani ${ }^{1}$, David Wood ${ }^{2}$, Hosein Kalantar Hormozi ${ }^{3}$ \\ ${ }^{1}$ Young Researchers and Elite Club, Ahvaz Branch, Islamic Azad University, Ahvaz, Iran \\ ${ }^{2}$ DWA Energy Limited, Lincoln, United Kingdom \\ ${ }^{3}$ Petroleum Engineering and Development Company (PEDEC), Ahvaz, Iran
}

(Received April 20, 2018; revised May 10, 2018; accepted May 11, 2018; available online May 20, 2018)

\section{Citation:}

Mohamadian, N., Ghorbani, H., Wood, D., Hormozi, H.K. Rheological and filtration characteristics of drilling fluids enhanced by nanoparticles with selected additives: an experimental study. Advances in Geo-Energy Research, 2018, 2(3): 228-236, doi: 10.26804/ager.2018.03.01.

Corresponding author:

*E-mail: dw@dwasolutions.com

Keywords:

Clay nanoparticles

xanthan

drilling fluid loss control

rheology

drilling mud filtration

\begin{abstract}
:
The suspension properties of drilling fluids containing pure and polymer-treated (partiallyhydrolyzed polyacrylamide or Xanthan gum) clay nanoparticles are compared with those of a conventional water-and-bentonite-based drilling fluid, used as the reference sample. Additionally, the mud weight, plastic viscosity, apparent viscosity, yield point, primary and secondary gelatinization properties, $\mathrm{pH}$, and filtration properties of the various drilling fluids studied are also measured and compared. The performance of each drilling fluid type is evaluated with respect in terms of its ability to reduce mud cake thickness and fluid loss thereby inhibiting differential-pipe-sticking. For that scenario, the mud-cake thickness is varied, and the filtration properties of the drilling fluids are measured as an indicator of potential well-diameter reduction, caused by mud cake, adjacent to permeable formations. The novel results show that nanoparticles do significantly enhance the rheological and filtration characteristics of drilling fluids. A pure-clay-nanoparticle suspension, without any additives, reduced fluid loss to about $42 \%$ and reduced mud cake thickness to $30 \%$ compared to the reference sample. The xanthan-gum-treated-clay-nanoparticle drilling fluid showed good fluid loss control and reduced fluid loss by $61 \%$ compared to the reference sample. The presence of nanofluids also leads to reduced mud-cake thicknesses, directly mitigating the risks of differential pipe sticking.
\end{abstract}

\section{Introduction}

Nanotechnology offers many potential benefits associated with improved performance of drilling fluids. The high surface area of nanoparticles compared to an equal mass of coarser-diameter particles improves their strength and electrical properties, and potentially makes them more chemically reactive (Shchukin and Sukhorukov, 2004; Godson et al., 2010; Rao, 2010). The higher surface-area-to-volume ratio of nanoparticles makes them more reactive and less impacted by compressive strains (Kohler and Fritzsche, 2007). Also, any defects in the nanoparticles tend to have greater impacts on the mechanical properties of the nanofluids than those fluids comprised of coarser particles (Kelsall et al., 2005).

For the above reasons, research on nanofluid applications in the drilling industry have expanded very rapidly over the past decade (Sarkar et al., 2015). Nanofluids, for which useful properties were first evaluated by Choi and Eastman (1995) are manufactured colloidal materials comprising of a base fluid and the nanoparticles. The presence of the nanoparticles significantly enhances all aspects of performance regarding the chemical, rheological, electrical thermal and mechanical properties of the carrier base fluids (Baghbanzadeh et al., 2014). There are many alternatives that are used for the base fluids. Many use water, but a range of organic liquids, including various oils, ethylene, glycols, lubricants, refrigerants, etc. are also used for base fluids, as are polymers and other easily produced and stable fluids (Sarkar, 2011).

Nanosized particles as suspensions in the base fluids typically lead to improved fluid stability, reducing the chances of sedimentation of the nanoparticles and the potential blockage of narrow apertures in tubulars or pore throats in rock formations (Karthikeyan et al., 2008). Consequently, employing an appropriate nanoparticle dispersion method is important in manufacturing stable suspensions. Hybrid nanofluid, i.e., 


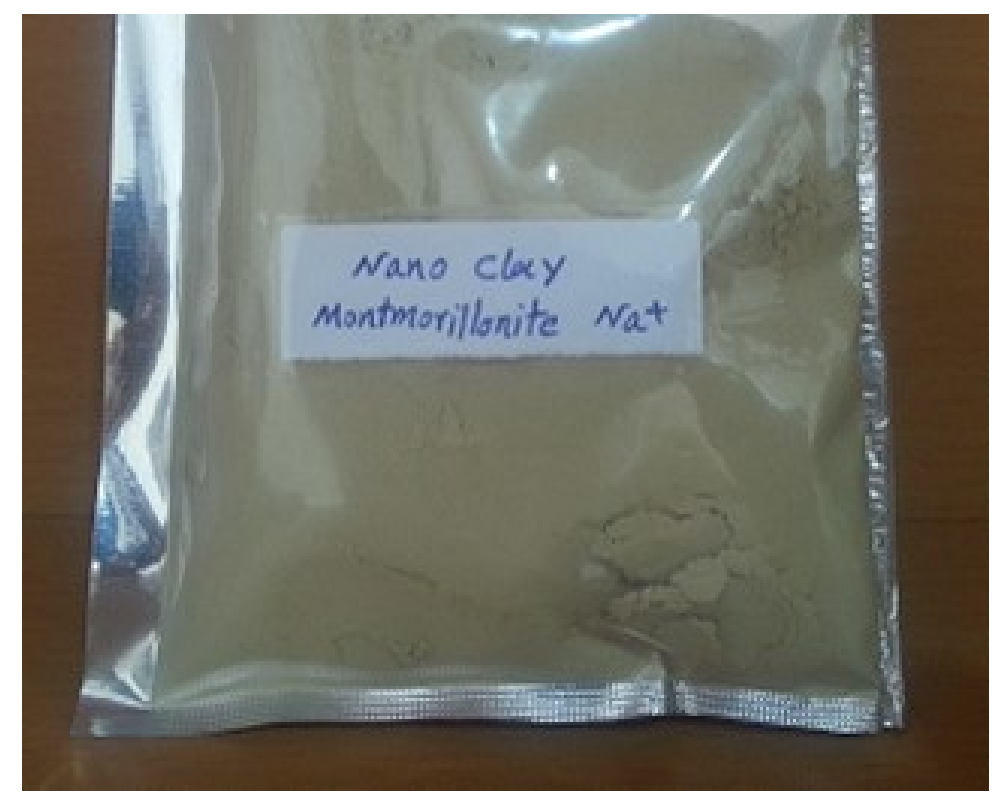

Fig. 1. Nano-clay montmorillonite used in this study: Source: Sigma-Aldrich Corporation. https://www.sigmaaldrich.com/technicaldocuments/articles/materials-science/nanomaterials/nano-minerals-nanoclays.html (accessed May, 2018).

suspending dissimilar nanoparticles in a base fluid either as mixtures or composites, also possess potentially beneficial properties (Sarkar et al., 2015). Employing nanomaterials to specifically enhance the properties of drilling fluids has been studied in detail over the past ten years or so (Mokhatab et al., 2006; Amanullah et al., 2009; Amanullah and Al-Abdullatif, 2010; Saket et al., 2011; Price-Hoelscher et al., 2012; Sharma et al., 2012; Abdou et al., 2013; Agarwal et al., 2013; PriceHoelscher and De Stefano, 2013; Baghbanzadeh et al., 2014; Fakoya and Shah, 2014; Ismail et al., 2014). Specifically, studies of the effects of different nanomaterials on rheological, filtration, lubrication and thermal properties of drilling fluids, have demonstrated that the presence of nanoparticles leads to improvement of many fluid characteristics. This includes applications in high temperature-high pressure (HT/HP), other deep wells (Abdo et al., 2013) and for so-called "smart" well designs (Igor et al., 2006; Amin and Abu el-Hassan, 2015). More generally, nano drilling fluids now tend to be classified as simple or advanced, depending upon nanoparticle concentrations and materials used (Amanullah et al., 2009).

Prior to nanoparticle deployment in drilling fluids, clay minerals have long been used to optimize the performance of drilling fluid. The layered structures of clay minerals composed of various polymeric silicate sheets incorporating different metal and $\mathrm{OH}^{-}$ions provide them with beneficial properties for industrial applications (Kloprogge et al., 1999). The cation exchange capacity (CEC) is a useful metric for characterizing clay materials (Uddin, 2008) and assess their suitability for use in drilling fluids. It measures the capacity of the negatively charged surfaces of clay minerals to adsorb cations, such as $\mathrm{Al}^{3+}, \mathrm{Ca}^{2+}, \mathrm{Mg}^{2+}, \mathrm{Mn}^{2+}, \mathrm{Zn}^{2+}, \mathrm{Cu}^{2+}, \mathrm{Fe}^{2+}$, $\mathrm{Na}^{+}, \mathrm{K}^{+}$, and $\mathrm{H}^{+}$. The plate-like crystalline forms of clay minerals, when dispersed in water, leads to an increase in fluid viscosity and a reduction in mud filtration by blocking the pore throats in permeable formation.
Here, we investigate clay nanoparticles as the base material for low-solid-water-based drilling fluids and compare, in a novel way, their properties and performance when modified with two biopolymer drilling fluid additives. Key drilling fluid properties including rheology and filtration characteristics are measured experimentally. Also, the performances of the different drilling fluid samples are compared for different concentrations of the base fluid and the additive material. We show that nanoparticles can potentially reduce formation damage related to solid invasion into the formation that plugs permeability. They can also increase the yield and performance of multi-functional drilling fluids, because they consume less additives and thereby reduce costs. We specifically compare the rheology, yield and performance of low-solid drilling fluids with conventional water-based systems. We also risk assess the potential for differentially-stuck drill pipe stuck in terms of the thickness of the mud cake formed.

\section{Experiment}

\subsection{Chemical and mineralogical studies}

The materials used in this study include nano-clay montmorillonite, which was supplied by Sigma-Aldrich Corporation (Fig. 1). The mineralogical composition of the nano-clay montmorillonite samples was determined by X-ray powder diffraction (XRD) analysis and the chemical composition of the samples (major and trace elements) was determined using $\mathrm{X}$-ray fluorescence techniques (XRF). Tables 1 and 2 list the $\mathrm{XRF}$ analysis and the physio-chemical characterization of the nanoparticles, respectively.

Xanthan gum and hydrolyzed polyacrylamide (PHPA) drilling additive were supplied by Pars Drilling Fluids Service Company. 
Table 1. XRF analysis of nano-clay montmorillonite used as a drilling fluid additive in this study.

\begin{tabular}{llllllllll}
\hline Component & $\mathrm{Na}_{2} \mathrm{O}$ & $\mathrm{Mgo}$ & $\mathrm{Al}_{2} \mathrm{O}_{3}$ & $\mathrm{SiO}_{2}$ & $\mathrm{~K}_{2} \mathrm{O}$ & $\mathrm{CaO}$ & $\mathrm{TiO}_{2}$ & $\mathrm{Fe}_{2} \mathrm{O}_{3}$ & $\mathrm{LOI}$ \\
\hline Content & 0.98 & 3.29 & 19.60 & 50.95 & 0.86 & 1.97 & 0.62 & 5.62 & 15.45 \\
\hline
\end{tabular}

Table 2. Physical and mechanical properties of the nano-clay montmorillonite used in this study as a drilling fluid additive.

\begin{tabular}{ll}
\hline Mineral type & Montmorillonite \\
\hline Density & $300-370 \mathrm{~kg} / \mathrm{m}^{3}$ \\
Particle size & $1-2 \mathrm{~nm}$ \\
Specific surface area & $220-270 \mathrm{~m}^{2} / \mathrm{gr}$ \\
Electrical conductivity & $25 \mathrm{MV}$ \\
Ion exchange coefficient & $48 \mathrm{meg} / 100 \mathrm{gr}$ \\
Space between the particles & $60 \mathrm{~A}^{\circ}$ \\
Color & Yellow \\
Humidity & $1 \%-2 \%$ \\
\hline
\end{tabular}

\subsection{Drilling fluid formulation and preparation proce- dure}

Traditionally, bentonite is used to control several specific drilling fluid characteristics, such as cuttings transport to the surface, bit lubrication, applying hydrostatic pressure within the wellbore, wellbore sealant limiting fluid loss, etc. A key property of bentonite is that it expands its volume some tenfold when hydrated, creating a viscous, slippery, gel-like slurry providing lubrication and other benefits. The addition of bentonite to a drilling fluid typically improves its wellcontrol capabilities and minimizes its fluid loss to permeable formations by enhancing filter cake formation on the wellbore walls (Gray and Darley, 1988; Lyons and Plisga, 2004). However, the use of bentonite does have some drawbacks such as the relatively high mud cake thickness it promotes and its cost. A mud cake that is too thick has the potential to exacerbate several drilling risks including, pipe sticking and high fluid loss.

Enhancing the performance of clay-based drilling fluid properties, particularly with nanoparticle additives is therefore of significant interest to the drilling industry. Possibility to improve the rheological and filtration properties of conventional drilling fluids clearly exist by combining them with suitable nano fluids appropriate rheological and filtration properties (Chang et al., 2007; Karthikeyan et al., 2008).

For the experiments conducted in this study, the base component of the water-based drilling fluid samples studied was prepared by adding $350 \mathrm{ml}$ of fresh water into a laboratory flask. For the bentonite-based fluid samples, $16 \mathrm{~g}$ of bentonite was poured into the fresh water and then mixed by a highspeed mixer for $15 \mathrm{~min}$ (API, 2009). For the nano-based fluid samples $2 \mathrm{~g}$ of montmorillonite clay nanoparticle were used as the base. These particles were dispersed in fresh water using ultrasound. $1 \mathrm{~g}$ of xanthan gum and $1 \mathrm{~g}$ of partially-hydrolyzed polyacrylamide (PHPA) were added to the nano-suspension separately and mixed for $15 \mathrm{~min}$. Xanthan gum, sometimes referred to as "XC polymer" is a polysaccharide secreted by the bacteria genus Xanthomonas campestris. Xanthan gum is a useful additive to water-based drilling fluids, because it provides non-Newtonian mud rheology with a characteristically flat velocity profile in annular flow that is a necessary requirement in low-density drilling fluids to efficiently lift rock cuttings. PHPA is a commonly used drilling fluid additive that assists well control by extending the effects of bentonite clay in low-solids mud recipes and helps to seal microfractures.

The experimental recipes of water-based drilling fluids studied are listed in Table 3.

The properties of the drilling fluid samples described were measured in accordance with the American Petroleum Institute (API) standards (Kloprogge et al., 1999). Viscosity data was obtained using a Fann-32 VG meter, and the data analyzed by applying the Bingham plastic model used for conventional water-based drilling fluids (Lyons and Plisga, 2004; Baker Hughes, 2006). The rheological parameters including, plastic and apparent viscosity, yield point and gel strength of all drilling fluid samples were calculated from their measured fluid properties. The drilling fluid samples studied are designated the letter codes identified in Table 1:

A: conventional bentonite-based drilling fluid

B: nano drilling fluid with nanoparticles of montmorillonite clay

C: nano drill fluid with Xanthan gum additive

D: nano drilling fluid with partially-hydrolyzed polyacry-

Table 3. Four drilling fluid recipes evaluated experimentally.

\begin{tabular}{lllllll}
\hline Sample & Sample type & Water & Bentonite & $\begin{array}{l}\text { Clay montmorillonite } \\
\text { nanoparticles }\end{array}$ & Xanthan gum & \multicolumn{2}{c}{ (Polyacrylamide) } \\
PHPA
\end{tabular}




\section{Mud Weight Comparisons}

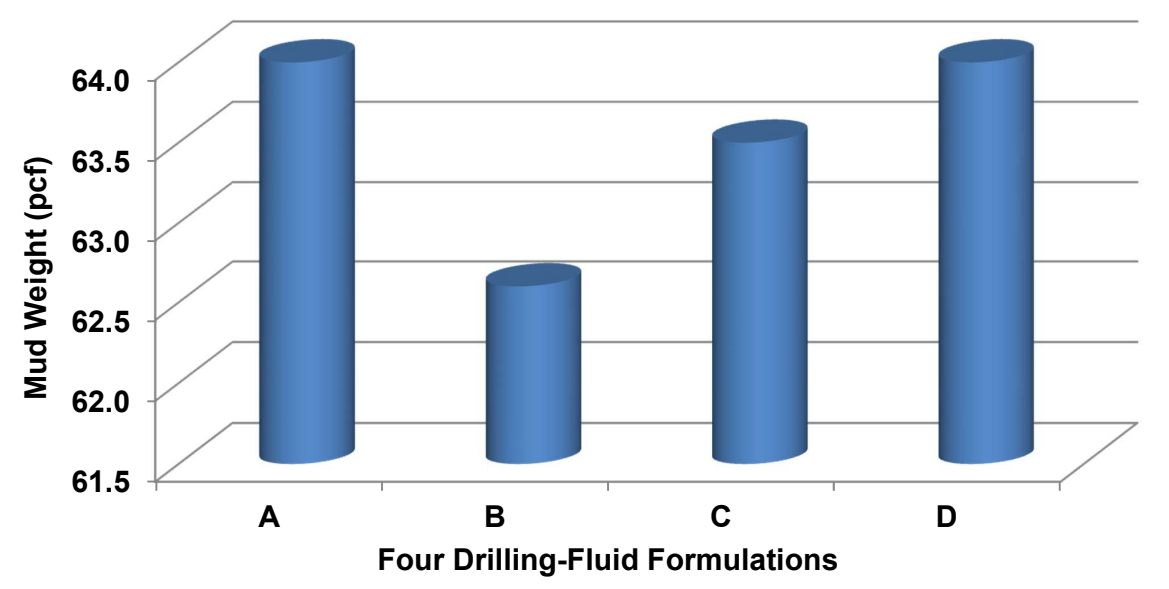

Fig. 2. Mud weight of the four different samples of drilling fluids studied: A is bentonite-based; B is with nanoparticles of montmorillonite clay; C is nano drilling fluid plus Xanthan gum; and D is nano drilling fluid plus PHPA. MW is mud weight in pounds per cubic foot.

lamide (PHPA) additive

\section{Results and discussion}

\subsection{Inhibition properties}

Drilling fluid (mud) weight is a critical metric influencing the well-control capabilities of a drilling fluid. Although it is often desirable to use drilling fluids with low solids contents to reduce the wear of mechanical parts and downhole tools and inhibit formation damage, drilling fluids with low solids must maintain densities/mud weights suitable to control a well and prevent blowouts. Nanoparticles at very low concentrations have the potential to provide drilling fluids with the desired properties with minimum impacts on their mud weights, thereby avoiding the need to add substantial quantities of other solid materials. The impact of the nanoparticles and other additive on the mud weight of the drilling fluid is depicted in Fig. 2. The nanoparticles did not reduce the mud weight significantly, particular in formulations $\mathrm{C}$ and $\mathrm{D}$ with the Xanthan gum and PHPA additives present. These results indicate that nano-drilling fluid formulations can be prepared with suitable mud weights.

Drilling fluid $\mathrm{pH}$ is the most important factor in tubular corrosion control. It also influences the equilibrium of reactions that impact the chemical structure and properties of drilling fluids. In particular, significant impacts on the rheological and filtration properties of drilling fluids, caused by $\mathrm{pH}$ and electrolyte concentration variations, are well known (Azar and Lummus, 1975; Kelessidis et al., 2007; Pilgrun and Arameley, 2013). This makes it desirable to maintain the drilling fluid $\mathrm{pH}$ in the alkaline range. Therefore, values of $\mathrm{pH}=8$ were established and maintained for the four drilling fluid samples studied.

\subsection{Rheological properties}

Lifting of cuttings by drilling fluids requires appropri- ate cuttings suspension properties, i.e., high-viscosity, shearthinning thixotropic properties. In the oilfield, funnel viscosity $(\mathrm{FV})$, apparent viscosity (AP), plastic viscosity (PV), yield point (YP), low-shear viscosity (LSV) and low-shear-rate viscosity (LSRV) and gel strengths (GS) are the metrics typically used to describe drilling fluid viscosity and the rheological properties. The gel strength is the shear stress of a drilling fluid that is measured at a low shear rate after the drilling mud has been static for a certain period of time. Two or three gel-strength readings are typically taken: 1 ) after the mud has remained in a static condition for 10 seconds (GSi); 2) after the mud has remained in a static condition for 10 minutes (GSs); and, 3) after the mud has remained in a static condition for 10 minutes (GSt).

It is the small size of clay nanoparticles $(<1$ nanometre) that is valuable for drilling fluid performance due to their negligible abrasive forces providing lower kinetic energy to the fluids (Kosuri, 2008; Amanullah et al., 2009; Vipulanandan and Mohammed, 2015). Their platy crystalline form provides them with a beneficial high surface-area-to-volume ratio which makes them more effective than larger particles (Riveland, 2013). The nano-sized plates are dispersed in fresh water assisted by water's polarity molecular property creating a more viscous fluid compared to high-volume-bentonite-based drilling fluids. Recipes that mix nanoparticles with particles of larger sizes is now proven to be economically beneficial for drilling fluids (Cheng et al., 2007). Filtration studies (Brigatti et al., 2006; Shakib et al., 2015) have shown that clay nanoparticles increase the plastic viscosity of drilling fluids to a greater degree than other additives. They do so because mechanical friction that exists between the nanoparticles themselves and between the clay nanoparticles and the liquid phase of the drilling fluid (Brigatti et al., 2006; Shakib et al., 2015). The electrical resistivity of a drilling fluid decreases with increasing bentonite and clay nanoparticle content, caused by the dispersal of charged clay sheets. This dispersal also increases the plastic viscosity (PV), apparent viscosity (AV), yield point (YP) and gel strength (GS) of a drilling fluid 


\section{Drilling Fluid Properties: PV, AV, YP}

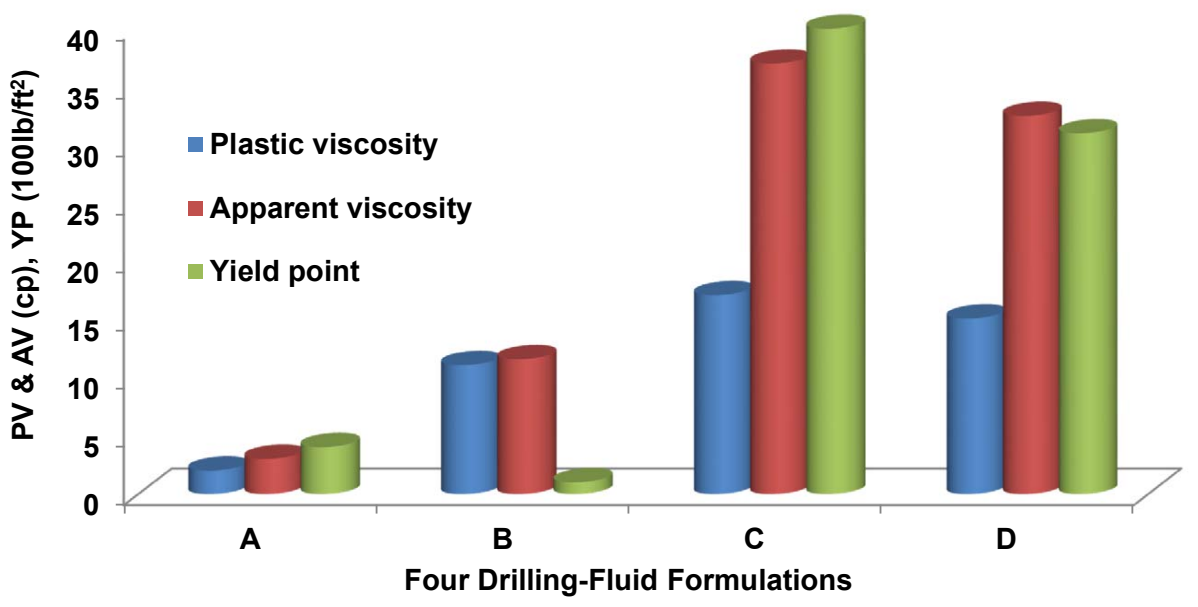

Fig. 3. Rheological properties of the four different samples of drilling fluids studied: A is bentonite-based; B is with nanoparticles of montmorillonite clay; $\mathrm{C}$ is nano drilling fluid plus Xanthan gum; and D is nano drilling fluid plus PHPA. PV is plastic viscosity, AV is apparent viscosity, and YP is yield point.

\section{Primary/Secondary Gel Strength}

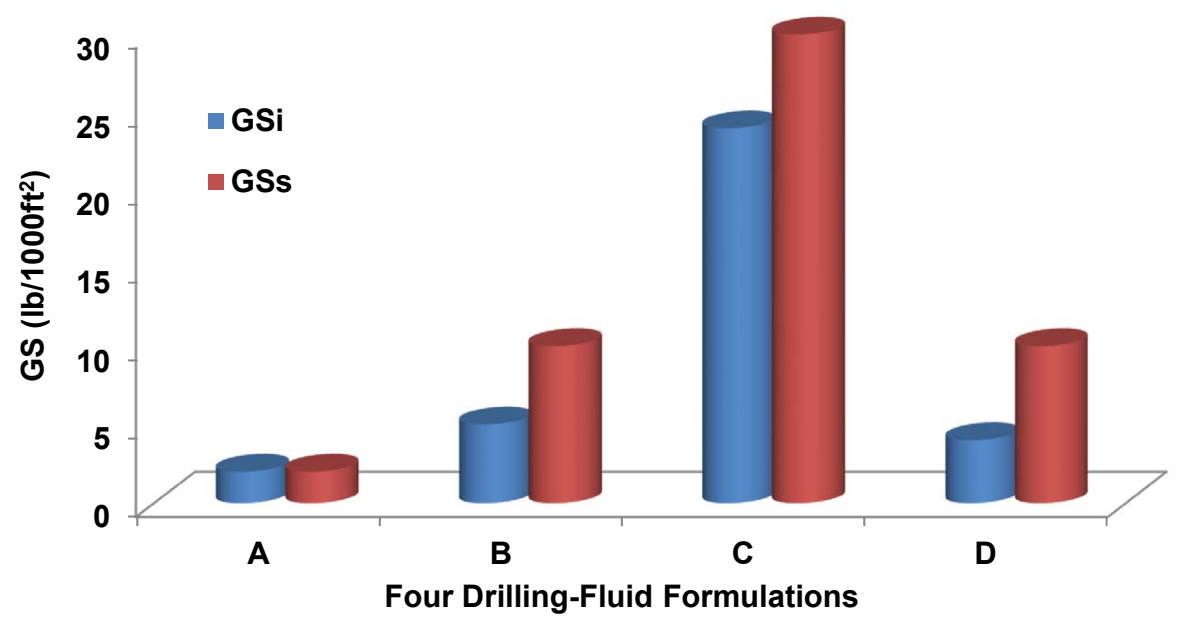

Fig. 4. Primary and secondary gel strengths of the four different samples of drilling fluids studied: A is bentonite-based; B is with nanoparticles of montmorillonite clay; C is nano drilling fluid plus Xanthan gum; and D is nano drilling fluid plus PHPA. GSi is the initial shear-strength measure (10-sec) and GSs (10-min) is the secondary shear strength measure.

(Vipulanandan and Mohammed, 2014).

Rheological properties and gel strengths determined for the drilling fluid samples studied are compared in Figs. 3 and 4.

Nano-based drilling fluids, in both pure form (Sample B) and treated samples with polymers (Samples C and D) clearly possess enhanced viscosity and rheological properties (Figs. 3 and 4) compared to conventional bentonite-based drilling fluids (Sample A). While the viscosities and the yield points of the drilling fluids with treated clay nanoparticles (Samples $\mathrm{C}$ and D) have increased significantly, the presence of clay nano-particles has not increased the mud weight of the drilling fluid (Fig. 2). The drilling fluid viscosity achieved by using $2 \mathrm{~g}$ of clay nanoparticles is about seven-times greater than the conventional $16 \mathrm{~g}$ bentonite sample. This highlights a key benefit of employing clay nanoparticles for formulations of low-solid drilling fluid systems.
The improved gel-strength properties of drilling fluids with nanoparticles (Fig. 4) also enhances the transmission characteristics associated with lifting drilling cuttings to the surface, i.e., it maintains drilling cuttings in a suspended state in the drilling fluid for a longer period when wellbore circulation stops. Figs. 3 and 4 highlight the impressive performance of nano drilling fluids treated with Xanthan gum as an additive (Sample C), i.e., its viscosity, yield point and gel strength are better than pure nano-based fluids by about a factor of two.

Table 4. Reduction in mud filtrate (\%) compared to conventional bentonite-based drilling fluid sample A achieved by drilling fluid samples B,

$$
\text { C, D. }
$$

\begin{tabular}{lll}
\hline B & C & D \\
\hline $42.30 \%$ & $61.53 \%$ & $34.61 \%$ \\
\hline
\end{tabular}


Fluid-Loss Characteristics of Four Drilling-Fluid Formulations

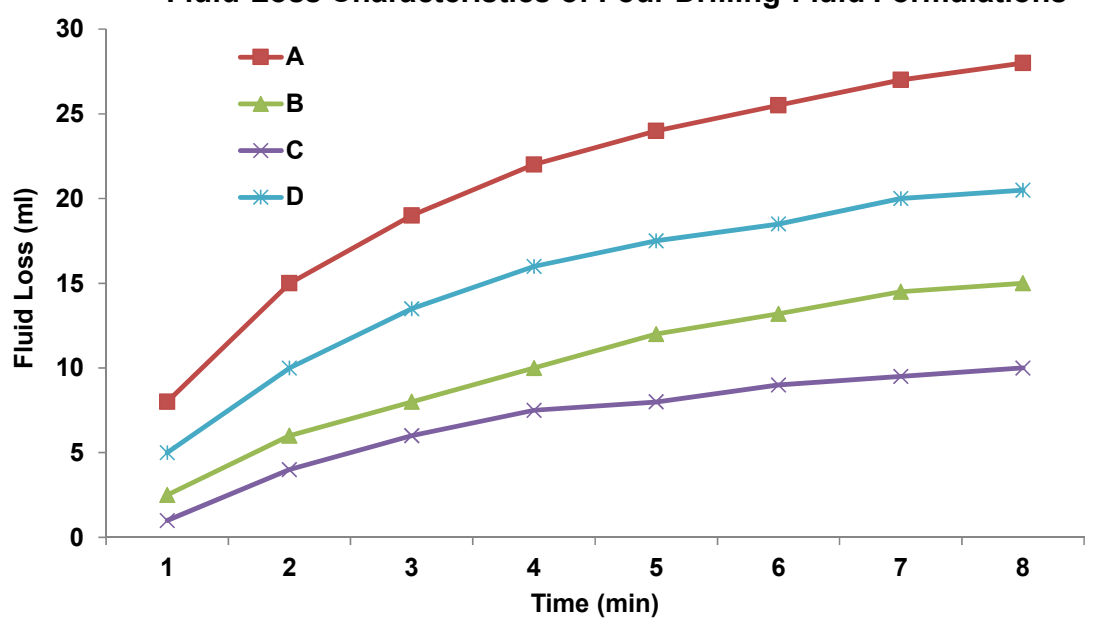

Fig. 5. Fluid-loss characteristics determined by standard API filtration tests for the four different samples of drilling fluids studied: A is bentonite-based; B is with nanoparticles of montmorillonite clay; C is nano drilling fluid plus Xanthan gum; and D is nano drilling fluid plus PHPA.

\subsection{Filtration properties}

Filtrate loss is an important characteristic of a drilling fluid that needs to be controlled to reduce potential formation damage and avoid high operating costs associated with the replacement of drilling fluid losses. Drilling fluids require fundamental properties that help to seal porous and permeable formations as quickly as possible with thin and slick filter cakes to avoid or minimize fluid losses (Annis et al., 1996). As well as fluid losses, thick filter cakes and excessive filtration increase the risk of tight hole occurrences while drilling, due to the increased torque and drag on the drill string. This in turn increases the potential for stuck pipe, lost circulation, poor quality well log data, and formation damage (Baker Hughes, 2006). Full loss of circulation of the drilling fluid while drilling is an undesirable and potentially hazardous/catastrophic outcome when encountered during drilling operations (Saket et al., 2011). In conventional reservoirs fluid loss typically develops in porous and permeable formation with pore throats between $0.1 \mu \mathrm{m}-1 \mathrm{~mm}$ diameter. In such circumstances, lostcirculation materials (LCMs) made up of particles of the same diameter are typically able to inhibit fluid flow from the wellbore into the conventional reservoirs. However, in the pore size diameters in tight reservoirs such as shales typically exist in the diameter range $10 \mathrm{~nm}$ to $0.1 \mu \mathrm{m}$. In these tight formations conventional LCM is often too large in its particle size to have the desired fluid flow control. In these tight reservoir conditions nanoparticles are often able to control fluid loss from the wellbore in a positive way, due to their appropriate particle sizes, hydrodynamic properties and the area to volume ratios (Fink, 2012). Using clay nanoparticles results in a reduction of water loss from the liquid phase of drilling fluid, as modelled by Saket et al. (2011).

Taking the mud filtrate loss from the conventional bentonite-based drilling fluid (Sample A) as the base, the fluid losses in terms of the quantity of mud filtrate are listed in Table 4 in percentage terms for the drilling samples B, C, D.
Clearly, fluid losses are reduced for all the nano-drilling fluids compared to conventional bentonite-based drilling fluids (Fig. 5 ), in particular that treated with Xanthan gum (Sample C).

These results demonstrate that nanoparticles in drilling fluids provide better control of both the fluid loss to the formation and the initial spurt loss (i.e., the instantaneous volume of liquid to pass through a filter medium prior a competent and effective mud cake is developed). They also further justify the assertion that the right combination of larger particles and nanoparticles in a drilling fluid recipe is likely to result in economic benefits (Cheng et al., 2007). Nanoparticles impact on permeability depends on the average particle size achieved in the mud cake (Shakib et al., 2015). The clay nanoparticles can effectively fit in between the larger particles in the mud cake and thereby block flow through it (Riveland, 2013). Due to the lack of positive charge in its plates, clay attracts water, as well as cations, and swells to several times its original volume. For larger-sized clay particles, this can result in an increase in material volume and filter cake thickness. However, clay nanoparticles are able to form a thinner (less material volume) and less permeable filter cake than conventional clay minerals such as bentonite.

Fig. 6 illustrates mud cakes for low solid and conventional drilling fluid systems.

\subsection{Mudcake thickness and its role in reducing the potential for stuck drill strings}

Stuck drill string increases drilling costs due to time wasted and potentially the additional costs associated with replacing part of the drill pipe and bottom-hole assembly or even sidetracking the wellbore. Differential sticking of a drill string is a consequence of the differential pressure exerted, typically by an overbalanced drilling-fluid column in the wellbore, on the drill string versus that acting upon the filter cake deposited on the walls of the wellbore as it penetrates permeable rock formations. This is most likely to occur when the drill string 


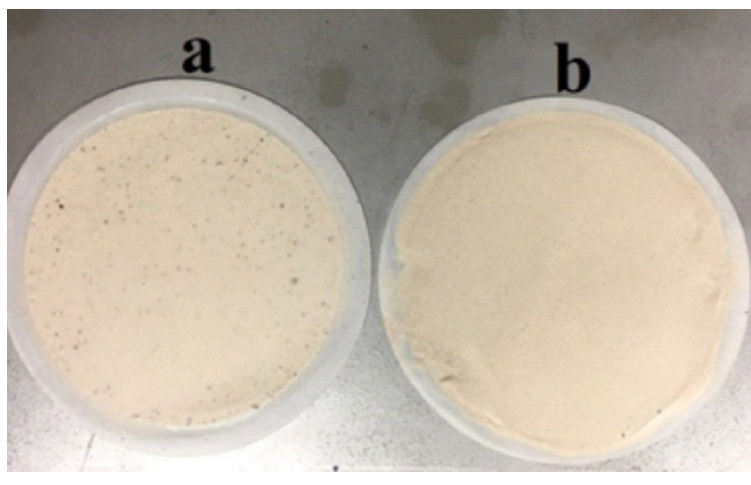

(a)

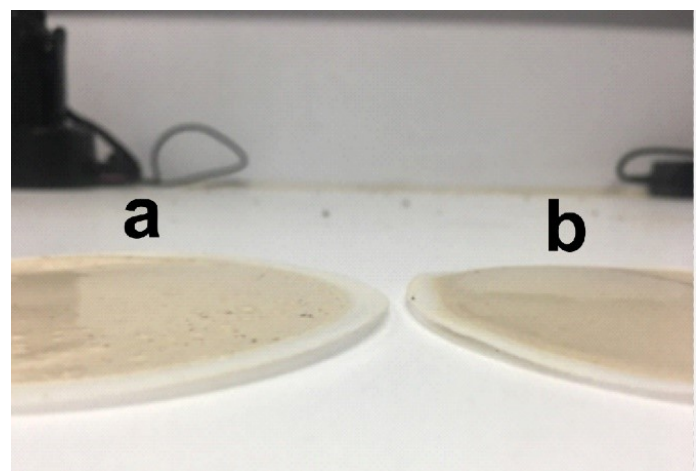

(b)

Fig. 6. Filter cake comparisons, (a): Xanthan-modified clay nanoparticle, (b): bentonite clay.

Table 5. Mud cake thickness variations for the four drilling-fluid formulations studied.

\begin{tabular}{|c|c|c|c|}
\hline \multicolumn{4}{|c|}{ Mud-cake Thickness (in units of $1 / 32$ inches) } \\
\hline A & B & $\mathrm{C}$ & $\mathrm{D}$ \\
\hline 6 & 4.2 & 4.3 & 4.5 \\
\hline \multicolumn{4}{|c|}{ Reduction in mud-cake Thickness (\%) relative to bentonite-based drilling fluid (Sample A) } \\
\hline & B & $\mathrm{C}$ & $\mathrm{D}$ \\
\hline & $30 \%$ & $28.33 \%$ & $25 \%$ \\
\hline
\end{tabular}

is held in a stationary mode during a connection or when a wellbore orientation survey is taken. Differential sticking of a drill string is typically associated with full circulation of the mud fluid occurring, but with no upward or downward mobility or rotary capability in the drill string, just pipe stretch and torque (Outmans, 1958; Ottesen et al., 1999). This means that the pulling force required to free stuck drill strings is greater in the presence of a thicker mud cake.

Mud-cake thickness is a key metric with several drilling and reservoir engineering impacts. Drilling fluids that produce mud cakes that are soft and thick enhance the risks of differential sticking and are, therefore, undesirable (Haden and Welch, 1961; Amanullah and Tan, 2000). Soft and thick mud cakes result in tight-hole conditions and a consequent increase in torque and drag on the drill string, leading to higher risks of differential sticking. Such mud cakes also encourage a cuttings bed to form in an integrated cuttings/mud cake deposit on the walls of the well bore, further exacerbating the thickness of the mud cake deposit. A thick mud cake negatively impacts open-hole well logging operations and makes the running in of casing strings more difficult, particularly in directional and horizontal wellbores (Maidla, 1987). Attempts to improve the physio-chemical characteristics of the mud cake through selective additives to drilling fluids are therefore worthy of close attention.

Drilling fluids that deposit particles as flocs (i.e., a loosely clumped masses of particles) on the borehole wall tends to increase the mud-cake thickness rapidly and significantly. Saltintolerant drilling fluids (e.g., those with bentonite and some polymer additives) are particularly prone to forming thick mud cakes for that reason. In contrast, oil-based drilling fluids tend to form thin mud cakes and were therefore preferred by many drillers because they reduced the risks of stuck drill strings (Chilingarian and Vorabutr, 1983). As oil-based drilling fluids are no longer permitted for environmental reasons in many jurisdictions, it is appropriate to find alternative drilling fluid formulations that also lead to thin mud cakes being formed.

Taking the conventional bentonite (Sample A) drilling fluid's mud cake thickness as the base, the thickness and the reduction of mud cake thickness where determined for drilling fluid formulations B, C, D. These are listed in Table 5.

Table 5 results highlight the significant, relative, mudcake-thickness reduction of drilling-fluid samples containing montmorillonite-clay nanoparticles (i.e., Samples B, C and D) compared to the conventional bentonite-based drilling fluid (Sample A) for the mud formulation with clay nanoparticles. As can be seen, clay nanoparticles are effective in reducing mud cake thickness.

\section{Conclusions}

The experimental studies and measurements of key drilling-fluid properties for formulations including clay nanoparticles demonstrate the relatively high performance of such drilling fluids compared to a conventional, bentonitebased formulation.

Clay nanoparticles reduced the amount of drilling-fluidwater loss by some $42 \%$ for the pure nano-fluid additive (Sample B), by some $34 \%$ for the treated sample with PHPA (Sample D), and by some $61 \%$ for the treated sample with Xanthan gum (Sample C), to a conventional, bentonite-based formulation (Sample A). The enhanced drilling performance characteristics of drilling fluid with clay nanoparticles and 
Xanthan gum (Sample C), especially in terms of its rheological and filtration properties is impressive compared to a conventional, bentonite-based drilling-fluid formulation (Sample A).

Furthermore, the good performance of nanoparticle drilling fluid formulations (samples B, C and D) significantly reduce the mud-cake thickness and fluid loss, leading to a significant reduction in the risks of stuck drill strings. They are also likely to improve well logging operations, the running of casing strings and reduce formation damage. There is scope to further optimize the performance of nanoparticle drilling fluids by adjusting them with other treated additives at various concentrations.

\section{Acknowledgments}

We thank the National Iranian South Oilelds Company (NISOC) for their assistance, and Mr. P. Ghazaeipour for providing helpful comments and suggestions.

Open Access This article is distributed under the terms and conditions of the Creative Commons Attribution (CC BY-NC-ND) license, which permits unrestricted use, distribution, and reproduction in any medium, provided the original work is properly cited.

\section{References}

Abdo, J., Haneef, M.D. Clay nanoparticles modified drilling fluids for drilling of deep hydrocarbon wells. Appl. Clay Sci. 2013, 86: 76-82.

Abdou, M.I., Al-Sabagh, A.M., Dardir, M.M. Evaluation of Egyptian bentonite and nano-bentonite as drilling mud. Egypt. J. Pet. 2013, 22(1): 53-59.

Agarwal, S., Phuoc, T.X., Soong, Y., et al. Nanoparticlestabilised invert emulsion drilling fluids for deep-hole drilling of oil and gas. Can. J. Chem. Eng. 2013, 91(10): 1641-1649.

Amanullah, M., Al-Abdullatif, Z. Preliminary test rresults of a water-based nanofluid. Paper presented at The 8th International Conf. \& Exhib. on Chemistry in Industry, Manama, Bahrain, 18-20 October, 2010.

Amanullah, M., Al-Tahini, A.M. Nano-technology-its significance in smart fluid development for oil and gas field application. Paper SPE 126102 presented at SPE Saudi Arabia Section Technical Symposium, Al-Khobar, Saudi Arabia, 9-11 May, 2009.

Amanullah, M., Tan, C.P. A non-destructive method of cake thickness measurement. Paper SPE 64517 presented at SPE Asia Pacific Oil and Gas Conference and Exhibition, Brisbane, Australia, 16-18 October, 2000.

Amin, M., Abu el-Hassan, K. Effect of using different types of nano materials on mechanical properties of high strength concrete. Constr. Build. Mater. 2015, 80: 116-124.

Annis, M.R., Smith, M.V. Drilling Fluids Technology. USA, Revised Edition Exxon Company,1996.

API. Recommended Practice for Field Testing Water-based Drilling Fluids. USA, American Petroleum Institute, 2003.

Azar, J.J., Lummus, J.L. The effect of drill fluid $\mathrm{pH}$ on drill pipe corrosion fatigue performance. Paper SPE 5516 presented at Fall Meeting of the Society of Petroleum
Engineers of AIME, Dallas, Texas, 28 September-1 October, 1975.

Baghbanzadeh, M., Rashidi, A., Soleimanisalim, A.H., et al. Investigating the rheological properties of nanofluids of water/hybrid nanostructure of spherical silica/MWCNT. Thermochim. Acta 2014, 578: 53-58.

Brigatti, M.F., Galan, E., Theng, B.K.G. Developments in Clay Science: Structures and Mineralogy of Clay Minerals. USA, Elsevier, 2006.

Caenn, R., Darley, H.C.H., Gray, G.R. Composition and Properties of Drilling and Completion Fluids. Oxford, United Kingdom, Gulf professional publishing, 2011.

Chang, T., Shih, J., Yang, K., et al. Material properties of Portland cement paste with nano-montmorillonite. J. Mater. Sci. 2007, 42(17): 7478-7487.

Chilingarian, G.V., Vorabutr, P. Drilling and Drilling Fluids. USA, Elsevier scentific publishing company, 1983.

Choi, S.U.S., Eastman, J.A. Enhancing thermal conductivity of fluids with nanoparticles. Paper ANL/MSD/CP-84938, CONF-951135-29 Presented at International Mechanical Engineering Congress and Exhibition, San Francisco, CA (United States), 12-17 November, 1995.

Evdokimov, I.N., Eliseev, N.Y., Losev, A.P., et al. Emerging petroleum-oriented nanotechnologies for reservoir engineering. Paper SPE 102060 presented at SPE Russian Oil and Gas Technical Conference and Exhibition, Moscow, Russia, 3-6 October, 2006.

Fakoya, M.F., Shah, S.N. Enhancement of filtration properties in surfactant-based and polymeric fluids by nanoparticles. Paper SPE 171029 presented at SPE Eastern Regional Meeting, Charleston, WV, USA, 21-23 October, 2014.

Godson, L., Raja, B., Lal, D.M., et al. Enhancement of heat transfer using nanofluids-an overview. Renewable Sustainable Energy Rev. 2010, 14(2): 629-641.

Haden, E.L., Welch, G.R. Techniques for preventing differential-pressure sticking of drill pipe a laboratory study. Paper API-61-036 presented at Drilling and Production Practice, New York, 1 January, 1961.

Hoelscher, K.P., Stefano, G.D., Riley, M., et al. Application of nanotechnology in drilling fluids. Paper SPE 157031 presented at SPE International Oilfield Nanotechnology Conference and Exhibition, Noordwijk, The Netherlands, 12-14 June, 2012.

Hoelscher, K.P., Young, S., Friedheim, J., et al. Nanotechnology application in drilling fluids. Paper OMC-2013-105 presented at Offshore Mediterranean Conference and Exhibition, Ravenna, Italy, 20-22 March, 2013.

Hughes, B. Drilling Fluids Reference Manual. Houston, Texas, 2006.

Ismail, A.R., Rashid, N.M., Jaafar, M.Z., et al. Effect of nanomaterial on the rheology of drilling fluids. J. Appl. Sci. 2014, 14(11): 1192-1197.

Javeri, S.M., Haindade, Z.M.W., Jere, C.B. Mitigating loss circulation and differential sticking problems using silicon nanoparticles. Paper SPE 145840 presented at SPE/IADC Middle East Drilling Technology Conference and Exhibition, Muscat, Oman, 24-26 October, 2011. 
Johannes, K.F. Petroleum Engineer's Guide to Oil Field Chemicals and Fluids. Oxford, United Kingdom, Gulf professional publishing, 2012.

Karthikeyan, N.R., Philip, J., Raj, B. Effect of clustering on the thermal conductivity of nanofluids. Mater. Chem. Phys. 2008, 109(1): 50-55.

Kelessidis, V.C., Tsamantaki, C., Dalamarinis, P. Effect of $\mathrm{pH}$ and electrolyte on the rheology of aqueous Wyoming bentonite dispersions. Appl. Clay Sci. 2007, 38(1-2): 8696.

Kelsall, R., Hamley, I.W., Geoghegan, M. Nanoscale Science and Technology. New York, USA, John Wiley \& Sons, 2005.

Kloprogge, J.T., Komarneni, S., Amonette, J.E. Synthesis of smectite clay minerals: A critical review. Clays Clay Miner. 1999, 47(5): 529-554.

Kosuri, D. Polyethylene-layered double hydroxides and montmorillonite nanocomposites: Thermal, mechanical and flame retardance properties. Texas, University of North Texas, 2008.

Lyons, W.C., Plisga, G.J. Standard Handbook of Petroleum and Natural Gas Engineering. Oxford, United Kingdom, Gulf professional publishing, 2011.

Maidla, E.E. Borehole Friction assessment and application to oilfield casing design in directional wells. Louisiana, LSU Historical Dissertations and Theses, 1987.

Michael, K.Ã., Fritzsche, W. Nanotechnology: An Introduction to Nanostructuring Techniques. New York, USA, John Wiley \& Sons, 2008.

Mokhatab, S., Fresky, M.A., Islam, M.R. Applications of nanotechnology in oil and gas E\&P. J. Pet. Technol. 2006, 58(4): 48-51.

Ottesen, S., Benaissa, S., Marti, J., et al. Down-hole simulation cell for measurement of lubricity and differential pressure sticking. Paper SPE 52816 presented at SPE/IADC Drilling Conference, Amsterdam, Netherlands, 9-11 March, 1999.

Outmans, H.D. Mechanics of differential pressure sticking of drill collars. Paper SPE 963 Presented at Annual Fall
Meeting of Southern California Petroleum Section, Los Angeles, California, 17-18 October, 1957.

Pilgun, S., Aramelev, A. Environmentally compatible drilling fluids. Paper SPE 166847 presented at SPE Arctic and Extreme Environments Technical Conference and Exhibition, Moscow, Russia, 15-17 October, 2013.

Rao, Y. Nanofluids: Stability, phase diagram, rheology and applications. Particuology 2010, 8(6): 549-555.

Riveland, F.A. Investigation of nanoparticles for enhanced filtration properties of drilling fluid. Trondheim, Norwegian University of Science and Technology, 2013.

Sarkar, J. A critical review on convective heat transfer correlations of nanofluids. Renewable Sustainable Energy Rev. 2011, 15(6): 3271-3277.

Sarkar, J., Ghosh, P., Adil, A. A review on hybrid nanofluids: recent research, development and applications. Renewable Sustainable Energy Rev. 2015, 43: 164-177.

Shakib, J.T., Kanani, V., Pourafshary, P. Nano-clays as additives for controlling filtration properties of waterbentonite suspensions. J. Pet. Sci. Eng. 2016, 138: 257264.

Sharma, M.M., Chenevert, M.E., Guo, Q., et al. A new family of nanoparticle based drilling fluids. Paper SPE 160045 presented at SPE Annual Technical Conference and Exhibition, San Antonio, Texas, 8-10 October, 2012.

Shchukin, D.G., Sukhorukov, G.B. Nanoparticle synthesis in engineered organic nanoscale reactors. Adv. Mater. 2004, 16(8): 671-682.

Uddin, F. Clays, nanoclays, and montmorillonite minerals. Metall. Mater. Trans. A 2008, 39(12): 2804-2814.

Vipulanandan, C., Mohammed, A. Effect of nanoclay on the electrical resistivity and rheological properties of smart and sensing bentonite drilling muds. J. Pet. Sci. Eng. 2015, 130: 86-95.

Vipulanandan, C., Mohammed, A.S. Hyperbolic rheological model with shear stress limit for acrylamide polymer modified bentonite drilling muds. J. Pet. Sci. Eng. 2014, 122: $38-47$. 